\section{Hyperhomo- cysteinemia in patients with diabetes mellitus with and without diabetic retinopathy}

\author{
Abstract \\ Objective To evaluate the prevalence of \\ hyperhomocysteinaemia in diabetic patients \\ with no diabetic retinopathy (no DR), with non- \\ proliferative diabetic retinopathy (NPDR) and \\ with proliferative diabetic retinopathy (PDR). \\ Research design and methods This
} prospective, case-control study, included 179 diabetic patients and 156 age-matched controls with no diabetes and no history of ocular disease, who were undergoing routine physical checkups. Plasma homocysteine levels of all study participants were measured using high-performance liquid chromatography (HPLC). Hyperhomocysteinaemia was defined when homocysteine levels were higher than $15 \mu \mathrm{mol} / 1$.

${ }^{1}$ Department of Ophthalmology Tel-Aviv Medical Center Sackler Faculty of Medicine Tel-Aviv University Tel-Aviv, Israel

${ }^{2}$ Institute of Chemical Pathology

Sheba Medical Center Sackler Faculty of Medicine Tel-Aviv University Tel-Aviv, Israel

\section{Correspondence:}

M Goldstein

Department of

Ophthalmology

Tel-Aviv Medical Center

6 Weitzman Street

Tel-Aviv 64239, Israel

Tel: + 972-3-6973408

Fax: + 972-3-6973870

E-mail: michgold@

netvision.net.il
Keywords: hyperhomocysteinemia; homocysteine; diabetes mellitus; diabetic retinopathy with diabetic retinopathy and partially explain occurring in these patients.

Eye (2004) 18, 460-465. doi:10.1038/sj.eye.6700702
M Goldstein'1, I Leibovitch', I Yeffimov'1,

S Gavendo², B-A Sela² and A Loewenstein ${ }^{1}$

\section{Introduction}

Hyperhomocysteinaemia is known to be a risk factor for vascular occlusive diseases. ${ }^{1-3}$ Elevated levels of plasma homocysteine have been found in patients suffering from peripheral vascular occlusions, such as coronary artery disease, ${ }^{4-7}$ cerebral vascular accidents, ${ }^{8}$ and deep-vein thrombosis, ${ }^{9}$ as well as from ocular vascular occlusions, such as retinal vein and retinal artery and anterior ischaemic optic neuropathy. ${ }^{10-17}$

High levels of plasma homocysteine are toxic to the vascular endothelium via the formation of free radicals. These free radicals cause direct injury to the endothelium by disrupting its integrity and exposing the underlying vascular matrix and smooth muscle, thus promoting a hypercoagulability state by the activation of platelets and thrombus formation. ${ }^{18-22}$

Increased plasma levels of homocysteine are found in any enzyme deficiency in the remethylation ${ }^{23}$ or transsulphuration ${ }^{24}$ process of methionine, and in a thermolabile variant of the enzyme MTHFR. ${ }^{25,26}$ It was found to be associated with age (probably due to decreased intake of folic acid and vitamin B12 ${ }^{27,28}$ ), male gender, ${ }^{27}$ renal failure, ${ }^{29-31}$ and medications. ${ }^{32-36}$

Diabetes is a microangiopathic atherosclerotic disease that affects the capillary bed in many body organs, mainly the kidneys, retina, and peripheral nervous system. Chronic hyperglycaemia is known to be the major determinant of diabetic retinopathy, ${ }^{37-42}$ perhaps modified by genetic or acquired features that vary from one individual to another. Numerous factors were described as having an effect on the development and progression of diabetic retinopathy, such as puberty, ${ }^{43,44}$ hypertension, ${ }^{45}$ and pregnancy. ${ }^{46}$ There is no explanation for the variation in the severity of diabetic retinopathy among diabetic 
patients with similar duration and control of the disease. This raises the possibility of there being other risk factors involved in the pathogenesis of diabetic retinopathy. Since diabetes is a microvascular occlusive disease, an adjuvant risk factor contributing to a hypercoagulability state, such as increased levels of plasma homocysteine, may accelerate or aggravate the development or progression of diabetic retinopathy.

The aim of our study was to evaluate the mean levels of homocysteine and to estimate the prevalence of hyperhomocysteinaemia among three subgroups of diabetic patients: those with no diabetic retinopathy (no DR), those with nonproliferative diabetic retinopathy (NPDR) and those with proliferative diabetic retinopathy (PDR), compared to a control group.

\section{Research design and methods}

All diabetic patients seen at the retina unit of the Tel-Aviv Medical Center from September 2000 through December 2001 who agreed to participate in the study and signed an informed consent were included. The study was approved by the Institutional Review Board/Ethics Committee.

A detailed medical history was obtained from each patient, including the duration of diabetes, the presence of renal disease, hypertension, cardiovascular disease, cerebrovascular disease, previous thromboembolic events, and current medications. Creatinine levels were assessed in all candidates in an attempt to identify those with renal failure. Patients with renal dysfunction known to be associated with high homocysteine levels ${ }^{29-31}$ were excluded from the study. Those treated with drugs like methotrexate, $^{32,33}$ fibrates, $^{34-35}$ or vitamin supplements ${ }^{28}$ (including ascorbic acid) in the previous 6 months, or patients consuming moderate amounts of alcohol were also excluded. ${ }^{47}$ All patients who participated in the study were treated with oral hypoglycaemic drugs, subcutaneous insulin injections or a combination of both. None of these conventionally used hypoglycaemic drugs are known to influence plasma levels of homocysteine.

The control group consisted of subjects of similar gender and age with no ocular disease who were undergoing routine physical examinations.

All subjects in the study and control group underwent a complete eye examination, including stereoscopic colour fundus photographs to all diabetic patients. All diabetic patients included in the study were subdivided into three categories (no DR, NPDR, and PDR) based on their funduscopic findings. The degree of diabetic retinopathy was determined in all patients by a clinical examination of one retina specialist (MG). The stereoscopic colour fundus photographs were assessed independently by a second retina specialist $(\mathrm{AL})$ to confirm the clinical classification. Both assessments were based on the grading diabetic retinopathy system as used in the ETDRS. ${ }^{48}$

The intra-individual coefficient of variation of plasma homocysteine was recently shown to be relatively low; ${ }^{49}$ therefore, one single plasma sample for evaluating homocysteine level was sufficient.

A 2-ml fasting blood sample was obtained from each participant. The blood was centrifuged within $30 \mathrm{~min}$ after collection at $3000 \mathrm{~g}$ for $6 \mathrm{~min}$. The plasma was removed and analysed for homocysteine by the HPLC method with fluorescent detection. ${ }^{50}$ Hyperhomocysteinaemia was defined when homocysteine levels were higher than $15 \mu \mathrm{mol} / 1$.

\section{Statistical analysis}

The Fisher exact test was used for comparing differences in proportions among the three groups. The two-sample $t$-test was used to examine differences in mean values between the groups. The Gabriel test was used for multiple comparisons. A $P$ value of $\leq 0.05$ was considered as being statistically significant.

\section{Results}

In total, 179 patients (92 males, 87 females) diagnosed with diabetes mellitus type II were included in the study. Patients were divided into three groups according to their ophthalmological findings as described previously. There were 62 patients with no DR (mean age $72.06 \pm 1.24$ years), 71 patients with NPDR (mean age 68.1 \pm 1.04 years) and 46 patients with PDR (mean age $69.2 \pm 1.36$ years). The control group consisted of 156 patients (80 males, 76 females, mean age $69 \pm 0.4$ years), with no diabetes and a normal funduscopic examination, who underwent routine ophthalmological examinations in our clinic.

There was no significant difference in age among the three groups of diabetic patients and the control group. The mean diabetes duration of $17.62 \pm 9.29$ years for the PDR patients was significantly longer than that for the NPDR and the no DR patients $(14.58 \pm 8.04$ and $11.96 \pm 8.13$, respectively; $P=0.001$ ). The mean plasma glucose level (normal value $<110 \mathrm{mg} / \mathrm{dl}$ ) of $146.32 \pm 43.48$ for the no DR patients was significantly lower than for the NPDR and the PDR groups $(181.04 \pm 58.03$ and $189.61 \pm 70.85$, respectively; $P<0.0001)$. No significant differences were found in the prevalence of hypertension, atherosclerotic cardiovascular disease, cerebrovascular accident, or thromboembolic events among the three groups and compared to the control group (Table 1). Table 2 summarizes the mean plasma homocysteine levels and the prevalence of 
Table 1 Prevalence of systemic diseases in diabetic patients and controls

\begin{tabular}{|c|c|c|c|c|c|c|c|c|}
\hline & \multicolumn{2}{|c|}{ No DR $(n=62)$} & \multicolumn{2}{|c|}{$N P D R(n=71)$} & \multicolumn{2}{|c|}{ PDR $(n=46)$} & \multicolumn{2}{|c|}{ Control $(n=156)$} \\
\hline & $n^{\prime}$ & $\%$ & $n^{\prime}$ & $\%$ & $n^{\prime}$ & $\%$ & $n^{\prime}$ & $\%$ \\
\hline HTN & 15 & 24.2 & 14 & 19.7 & 10 & 21.7 & 34 & 21.8 \\
\hline CVA & 3 & 4.8 & 4 & 5.6 & 3 & 6.5 & 7 & 4.5 \\
\hline IHD & 10 & 16.1 & 12 & 16.9 & 8 & 17.4 & 20 & 12.8 \\
\hline Thrombo & 1 & 1.61 & 1 & 1.4 & 0 & 0 & 0 & 0 \\
\hline
\end{tabular}

$\mathrm{HTN}=$ hypertension, $\mathrm{CVA}=$ cerebrovascular accident, $\mathrm{IHD}=$ ischaemic heart disease, Thrombo $=$ thromboembolic events, no $\mathrm{DR}=$ no diabetic retinopathy, $\mathrm{NPDR}=$ nonproliferative diabetic retinopathy, $\mathrm{PDR}=$ proliferative diabetic retinopathy.

Table 2 Plasma homocysteine levels and hyperhomocysteinaemia prevalence

\begin{tabular}{lccc}
\hline & Subjects $(n)$ & Homocysteine level $(\mu \mathrm{mol} / \mathrm{l} \pm S E)$ & Hyperhomocysteinaemia $(>15 \mu$ mol $/ \mathrm{l})$ \\
\hline No DR & 62 & $13.46 \pm 0.74$ & $22.42 \%$ \\
& & $(P=0.152)$ & $(P=0.40)$ \\
NPDR & 71 & $14.56 \pm 0.64$ & $36.6 \%$ \\
& & $(P=0.001)$ & $(P=0.032)$ \\
PDR & 46 & $15.86 \pm 1.34$ & $39.1 \%$ \\
& & $(P<0.0001)$ & $(P=0.011)$ \\
Control & 156 & $11.75 \pm 0.24$ & $16.82 \%$ \\
\hline
\end{tabular}

No $\mathrm{DR}=$ no diabetic retinopathy, NPDR = nonproliferative diabetic retinopathy, PDR = proliferative diabetic retinopathy.

hyperhomocysteinaemia in each group. Mean homocysteine levels were significantly elevated in the NPDR and PDR groups compared to the control group ( $P=0.001$ and $<0.0001$, respectively), but no significant difference was found between the no DR group and the control group $(P=0.152)$. The prevalence of hyperhomocysteinaemia was also higher in the NPDR and PDR groups compared to the control group ( $P=0.032$ and 0.011 , respectively), but no significant difference was found between the no DR group and the control group $(P=0.40)$.

\section{Conclusions}

The results of our study revealed a significantly higher prevalence of hyperhomocysteinaemia and higher levels of mean plasma homocysteine in diabetic patients with PDR and NPDR compared to a matched control group.

Numerous studies dealing with a possible correlation between hyperhomocysteinaemia and vascular complications in subjects with diabetes mellitus have appeared over the past few years. In analysing the Hoorn study, Hoogeveen et $a l^{51}$ concluded that

hyperhomocysteinaemia is a stronger risk factor for overall mortality in diabetic patients than among nondiabetic subjects. Ambrosch et al ${ }^{52}$ examined 65 patients with type II diabetes; 43 were found to have diabetic neuropathy and this subgroup had elevated levels of homocysteine and a higher prevalence of hyperhomocysteinaemia. Vaccaro et $a l^{53}$ studied 66 patients with type I diabetes and found similar plasma homocysteine levels in patients and healthy controls. In a subgroup of patients with proliferative retinopathy; however, homocysteine was significantly higher when compared to patients without retinopathy due to the genetic homozygote C677T mutation which was at least twice as frequent in the former. In another report of the Hoorn study, Hoogeveen et al ${ }^{54}$ looked for an association between homocysteine level and retinopathy among subjects with and without diabetes. They found a $12 \%$ prevalence of retinopathy in subjects with normal serum homocysteine level $(<16 \mu \mathrm{mol} / \mathrm{l})$ compared to $16.5 \%$ in individuals with higher serum levels of homocysteine ( $>16 \mu \mathrm{mol} / \mathrm{l})$. The odds ratio between retinopathy and hyperhomocysteinaemia was 0.97 in patients without diabetes and 3.44 in patients with diabetes.

It is known that proliferative diabetic retinopathy is augmented by retinal hypoxia. ${ }^{55-57}$ Homocysteine is toxic to the vascular endothelium and therefore induces thrombosis, and thus may play a role in aggravating the hypoxic state such as that seen in diabetic retinopathy by further closure of the capillary bed. Many of the abovequoted studies have shown that higher levels of plasma homocysteine were found in patients suffering from known microvascular complications of more severe or advanced stages of diabetes, among them diabetic neuropathy, nephropathy, and retinopathy. In addition, it had been suggested that hyperhomocysteinaemia in these advanced cases might be secondary to diabetic 
renal dysfunction. ${ }^{29}$ All participants included in our study had normal renal functions.

It is our contention that higher plasma levels of homocysteine in diabetic patients may play a role in accelerating the microvascular retinal changes and may, therefore, contribute to the severity of diabetic retinopathy. The prevalence of hyperhomocysteinaemia and mean plasma homocysteine levels in our diabetic retinopathy subgroups of patients were higher than in the control group, but there was no significant difference between the no DR subgroup and the control group. These findings may in part explain the possible progression of diabetic retinopathy in diabetic patients with higher homocysteine levels compared to diabetic patients with lower homocysteine levels who have no DR, although the shorter diabetes duration and lower plasma glucose levels in the no DR group compared to the NPDR and PDR groups are probably the most important contributing factors. Therefore, a longer follow-up period is needed to evaluate the long-term effects of homocysteine levels on the progression of diabetic retinopathy.

Since there are numerous factors influencing the development and progression of diabetic retinopathy, some of them yet unknown, we believe that hyperhomocysteinaemia is another contributing factor to microvascular angiopathy via thrombus formation in the capillaries and further impairment in blood supply to the affected tissue. We believe that plasma homocysteine should be assessed in all diabetic patients and that any existing hyperhomocysteinaemia should be treated with the aim of reducing the toxic effect of homocysteine and preventing further capillary closure and hypoxia.

Treatment of hyperhomocysteinaemia is easy, safe, and well tolerated. Folic acid supplement in a dose of $250 \mu \mathrm{g} /$ day in addition to the usual dietary intake was shown to be effective in reducing plasma homocysteine in young women, $^{58}$ and $400 \mu \mathrm{g} /$ day together with vitamin B6 and B12 was effective in the elderly population. ${ }^{59}$

Our lab is currently running a series of studies on the natural progression of diabetic retinopathy in diabetic patients with hyperhomocysteinaemia compared to patients with normal homocysteine levels. Validation of the possible role of homocysteine in the pathogenesis and progression of a microangiopathic vascular disease such as diabetic retinopathy, and the determination of a possible supplementary treatment policy warrant further investigation.

\section{References}

1 Clarke R, Daly L, Robinson K, Naughten E, Cahalane S, Fowler B et al. Hyperhomocysteinemia: an independent risk factor for vascular disease. N Engl J Med 1991; 324: 11491155.

2 D'Angelo A, Selhub J. Homocysteine and thrombotic disease [review]. Blood 1997; 90: 1-11.

3 Graham IM, Daly LE, Refsum HM, Robinson K, Brattstrom LE, Ueland PM. Plasma homocysteine as a risk factor for vascular disease. The European Concerted Action Project. JAMA 1997; 277: 1775-1781.

4 Stampfer MJ, Malinow MR, Willett WC, Newcomer LM, Upson B, Ullmann D et al. A prospective study of plasma homocysteine and risk of myocardial infarction in US physicians. JAMA 1992; 268: 877-881.

5 Wald NJ, Watt HC, Law MR, Weir DG, McPartlin J, Scott JM. Homocysteine and ischemic heart disease: results of a prospective study with implications regarding prevention. Arch Intern Med 1998; 158: 862-867.

6 Arnesen E, Refsum H, Bonaa KH, Ueland PM, Forde $\mathrm{OH}$, Nordrehaug JE. Serum total homocysteine and coronary heart disease. Int J Epidemiol 1995; 24: 704-709.

7 Nygard O, Nordrehaug JE, Refsum H, Ueland PM, Farstad M, Vollset SE. Plasma homocysteine levels and mortality in patients with coronary artery disease. N Engl J Med 1997; 337: 230-236.

8 Pery IJ, Refsum H, Morris RW, Ebrahim SB, Ueland PM, Shaper AG. Prospective study of serum total homocysteine concentration and risk of stroke in middle-aged British men. Lancet 1995; 346: 1395-1398.

9 den Heijer M, Koster T, Blom HJ, Bos GM, Briet E, Reitsma $\mathrm{PH}$ et al. Hyperhomocysteinemia as a risk factor for deepvein thrombosis. N Engl J Med 1996; 334: 759-762.

10 Biousse V, Newman NJ, Sternberg P. Retinal vein occlusion and transient monocular visual loss associated with hyperhomocysteinemia. Am J Ophthalmol 1997; 124: 257-260.

11 Loewenstein A, Winder A, Goldstein M, Lazar M, Eldor A. Bilateral retinal vein occlusion associated with 5,10methylenetetrahydrofolate reductase mutation. $\mathrm{Am} \mathrm{J}$ Ophthalmol 1997; 124: 840-841.

12 de Bruijne E, Keulen-de Vos G, Ouwendijk R. Ocular venous occlusion and hyperhomocysteinemia. Ann Intern Med 1999; 130: 78 .

13 Vine AK. Hyperhomocysteinemia: a risk factor for central retinal vein occlusion. Am J Ophthalmol 2000; 129: 640-644.

14 Loewenstein A, Goldstein M, Winder A, Lazar M, Eldor A. Retinal vein occlusion associated with methylenetetrahydrofolate reductase mutation. Ophthalmology 1999; 106: 1817-1820.

15 Pianka P, Almog Y, Man O, Goldstein M, Sela BA, Loewenstein A. Hyperhomocysteinemia in patients with anterior ischemic optic neuropathy, central retinal artery occlusion, and central retinal vein occlusion. Ophthalmology 2000; 107: 1588-1592.

16 Kawasaki A, Purvin VA, Burgett RA. Hyperhomocysteinemia in young patients with nonarteritic ischemic optic neuropathy. Br J Ophthalmol 1999; 83: 1287-1290.

17 Wenzler EM, Rademakers AJ, Boers GH, Cruysberg JR, Webers CA, Deutman AF. Hyperhomocysteinemia in retinal artery and retinal vein occlusion. Am J Ophthalmol 1993; 115: 162-167.

18 Harker LA, Slichter SJ, Scott CR, Ross R. Homocysteinemia: vascular injury and arterial thrombosis. N Engl J Med 1974; 291: $537-543$ 
19 Starkebaum G, Harlan JM. Endothelial cell injury due to copper-catalyzed hydrogen peroxide generation from homocysteine. J Clin Invest 1986; 77: 1370-1376.

20 van den Berg M, Boers GH, Franken DG, Blom HJ, Van Kamp GJ, Jakobs $\mathrm{C}$ et al. Hyperhomocysteinemia and endothelial dysfunction in young patients with peripheral arterial occlusive disease. Eur J Clin Invest 1995; 25: 176-181.

21 Stamler JS, Osborne JA, Jaraki O, Rabbani LE, Mullins M, Singel $\mathrm{D}$ et al. Adverse vascular effects of homocysteine are modulated by endothelium-derived relaxing factor and related oxides of nitrogen. J Clin Invest 1993; 91: 308-318.

22 Upchurch GR Jr, Welch GN, Fabian AJ, Freedman JE, Johnson JL, Keaney JF Jr et al. Homocystine decreases bioavailable nitric oxide by a mechanism involving glutathione peroxidase. J Biol Chem 1997; 272: 1712-1717.

23 Ogier de Baulny H, Gerard M, Saudubray JM, Zittoun J. Remethylation defects: guidelines for clinical diagnosis and treatment. Eur J Pediatr 1998; 157(Suppl 2): S77-S83.

24 Mudd SH, Skovby F, Levy HL, Pettigrew KD, Wilcken B, Pyeritz RE et al. The natural history of homocystinuria due to cystathionine beta-synthase deficiency. Am J Hum Genet 1985; 37: 1-31.

25 Kang SS, Zhou J, Wong PW, Kowalisyn J, Strokosch G. Intermediate homocystinemia: a thermolabile variant of methylenetetrahydrofolate reductase. Am J Hum Genet 1988; 43: 414-421.

26 Frosst P, Blom HJ, Milos R, Goyette P, Sheppard CA, Matthews RG et al. A candidate genetic risk factor for vascular disease: a common mutation in methylenetetrahydrofolate reductase. Nat Genet 1995; 10: 111-113.

27 Andersson A, Brattstrom L, Israelsson B, Isaksson A, Hamfelt A, Hultberg B. Plasma homocysteine before and after methionine loading with regard to age, gender and menopausal status. Eur J Clin Invest 1992; 22: 79-87.

28 Selhub J, Jacques PF, Wilson PW, Rush D, Rosenberg IH. Vitamin status and intake as primary determinates of homocysteinemia in an elderly population. JAMA 1993; 270: 2693-2698.

29 Bostom AG, Shemin D, Lapane KL, Miller JW, Sutherland P, Nadeau $\mathrm{M}$ et al. Hyperhomocysteinemia and traditional cardiovascular disease risk factor in end-stage renal disease patients on dialysis: a case-control study. Atherosclerosis 1995; 114: 93-103.

30 Gupta A, Robinson K. Hyperhomocysteinaemia and end stage renal disease. J Nephrol 1997; 10: 77-84.

31 van Guldener C, Robinson K. Homocysteine and renal disease. Semin Thromb Hemost 2000; 26: 313-324.

32 Broxson EH Jr, Stork LC, Allen RH, Stabler SP, Kolhouse JF. Changes in plasma methionine and total homocysteine levels in patients receiving methotrexate infusions. Cancer Res 1989; 49: 5879-5883.

33 Guttormsen AB, Ueland PM, Lonning PE, Mella O, Refsum $\mathrm{H}$. Kinetics of plasma total homocysteine in patients receiving high-dose methotrexate therapy. Clin Chem 1998; 44: 1987-1989.

34 Dierkes J, Westphal S, Luley C. Serum homocysteine increases after therapy with fenofibrate or bezafibrate. Lancet 1999; 354: 219-220.

35 Westphal S, Dierkes J, Luley C. Effects of fenofibrate and gemfibrozil on plasma homocysteine. Lancet 2001; 358: 39-40.

36 Blankenhorn DH, Malinow MR, Mack WJ. Colestipol plus niacin therapy elevates plasma homocysteine levels. Coron Artery Dis 1991; 2: 357-360.
37 Klein R, Klein BE, Moss SE, Davis MD, DeMets DL. The Wisconsin Epidemiologic Study of Diabetic Retinopathy. II. Prevalence and risk of diabetic retinopathy when age at diagnosis is less than 30 years. Arch Ophthalmol 1984; 102: 520-526.

38 Frank RN, Hoffman WH, Podgor MJ, Joondeph HC, Lewis RA, Margherio RR et al. Retinopathy in juvenile-onset type I diabetes of short duration. Diabetes 1982; 31: 874-882.

39 Palmberg P, Smith M, Waltman S, Krupin T, Singer P, Burgess $\mathrm{D}$ et al. The natural history of retinopathy in insulin-dependent juvenile-onset diabetes. Ophthalmology 1981; 88: 613-618.

40 DCCT Research Group. The effect of intensive treatment of diabetes in the development and progression of long-term complications in insulin-dependent diabetes. $N$ Engl J Med 1993; 329: 977-986.

41 UK Prospective Diabetes Study (UKPDS) Group. Intensive blood glucose control with sulphonylureas or insulin compared with conventional treatment and risk of complications in patients with type 2 diabetes (UKPDS 33). Lancet 1988; 352: 837-853.

42 Reichard P, Nilsson BY, Rosenquist U. The effect of longterm intensified insulin treatment on the development of microvascular complications of diabetes mellitus. $N$ Engl $J$ Med 1993; 329: 304-309.

43 Klein BEK, Moss SE, Klein R. Is menarche associated with diabetic retinopathy? Diabetes Care 1990; 13: 1038-1043.

44 Klein R, Klein BE, Moss SE, Davis MD, DeMets DL. Retinopathy in young-onset diabetic patients. Diabetes Care 1985; 8: 311-315.

45 UK Prospective Diabetes Study Group. Tight blood pressure control and risk of macrovascular and microvascular complications in type 2 diabetes: UKPDS 38. BMJ 1998; 317: 703-713.

46 Klein BEK, Moss SE, Klein R. Effect of pregnancy on progression of diabetic retinopathy. Diabetes Care 1990; 13: 34-40.

47 van der Gaag MS, Ubbink JB, Sillanaukee P, Nikkari S, Hendriks HF. Effect of consumption of red wine, spirits, and beer on serum homocysteine. Lancet 2000; 355: 1522.

48 Early Treatment Diabetic Retinopathy Study Research Group. Grading diabetic retinopathy from stereoscopic color fundus photographs-an extension of the modified Airlie House classification. ETDRS report number 10. Early Treatment Diabetic Retinopathy Study Research Group. Ophthalmology 1991; 98: 786-806.

49 Rossi E, Beilby JP, McQuillan BM, Hung J. Biological variability and reference intervals for total plasma homocysteine. Ann Clin Biochem 1999; 36(Part 1): 56-61.

50 Fiskerstrand T, Refsum H, Kvalheim G, Ueland PM. Homocysteine and other thiols in plasma and urine: automated determination and sample stability. Clin Chem 1993; 39: 263-271.

51 Hoogeveen EK, Kostense PJ, Jakobs C, Dekker JM, Nijpels $\mathrm{G}$, Heine RJ et al. Hyperhomocysteinemia increases risk of death, especially in type 2 diabetes. 5 -year follow-up of the Hoorn study. Circulation 2000; 101: 1506-1511.

52 Ambrosch A, Dierkes J, Lobmann R, Kuhne W, Konig W, Luley C et al. Relation between homocysteinemia and diabetic neuropathy in patients with Type 2 diabetes mellitus. Diabetes Med 2001; 18: 185-192.

53 Vaccaro O, Perna AF, Mancini FP, Iovine C, Cuomo V, Sacco $\mathrm{M}$ et al. Plasma homocysteine and microvascular 
complications in type 1 diabetes. Nutr Metab Cardiovasc Dis 2000; 10: 297-304.

54 Hoogeveen EK, Kostense PJ, Eysink PE, Polak BC, Beks PJ, Jakobs $\mathrm{C}$ et al. Hyperhomocysteinemia is associated with the presence of retinopathy in type 2 diabetes mellitus: the Hoorn study. Arch Intern Med 2000; 160: 2984-2990.

55 Aiello LP, Avery RL, Arrigg PG, Keyt BA, Jampel HD, Shah $\mathrm{ST}$ et al. Vascular endothelial growth factor in ocular fluid of patients with diabetic retinopathy and other retinal disorders. N Engl J Med 1994; 331: 1480-1487.

56 Aiello LP, Northrup JM, Keyt BA, Takagi H, Iwamoto MA. Hypoxic regulation of vascular endothelial growth factor in retinal cells. Arch Ophthalmol 1995; 113: 1538-1544.
57 Pe'er J, Shweiki D, Itin A, Hemo I, Gnessin H, Keshet E. Hypoxia-induced expression of vascular endothelial growth factor (VEGF) by retinal cells is a common factor in neovascularization. Lab Invest 1995; 72: 638-645.

58 Brouwer IA, van Dusseldorp M, Thomas CM, Duran M, Hautvast JG, Eskes TK et al. Low-dose folic acid supplementation decreases plasma homocysteine concentrations: a randomized trial. Am J Clin Nutr 1999; 69: 99-104.

59 Lobo A, Naso A, Arheart K, Kruger WD, Abou-Ghazala T, Alsous $\mathrm{F}$ et al. Reduction of homocysteine levels in coronary artery disease by low-dose folic acid combined with vitamins B6 and B12. Am J Cardiol 1999; 83: 821-825. 